\title{
'We are the ones that talk about difficult subjects': nurses in schools working to support young people's mental health
}

\author{
Authors: \\ Jennifer Spratt, School of Education, University of Aberdeen \\ Kate Philip, School of Education, University of Aberdeen \\ Janet Shucksmith, School of Health and Social Care, Teesside University \\ Alice Kiger, Centre of Academic Primary Care, University of Aberdeen \\ Dorothy Gair, Scottish Government
}




\section{'We are the ones that talk about difficult subjects': nurses}

\section{in schools working to support young people's mental}

\section{health}

Key words: School nurses, mental health, resilience, relationships, Scotland

\section{Abstract}

As health professionals in an educational setting, nurses in schools occupy a unique place in the spectrum of children's services. Yet the service is often overlooked and has been described as invisible (Crogan et al 2004). This paper draws on findings from a study, funded by the Scottish Government's National Programme for Improving Mental Health and Well-being, which explored the role of school nurses in promoting and supporting the mental health of children and young people. The school nursing service throughout the UK is at a pivotal point as its role is being redefined to align with moves across the NHS towards a public health model (Molloy and Caraher 2000). This paper therefore offers a timely overview of the mental health work of school nurses, and raises key issues for future work.

Interviews were conducted with 25 school nurse managers across Scotland. Interviewees claimed that the contribution of nurses in schools was distinctive, owing to the quality and consistency of relationship that they could offer, and the autonomy that the service allowed young people. However, significant challenges were reported in making this contribution, and tensions were evident in the conceptualisation of their role. The framework of resilience is used to discuss the findings on the significance of building relationships in promoting mental health. 


\section{Introduction - schools and mental health}

In the wake of concerns about the mental health of children in the UK (Green et al 2005) and Europe (World Health Organisation Europe 2005), coupled with calls for schools to be 'emotionally literate' (Weare 2004), mental health has become a focus of educational policy across the UK (Scottish Executive 2004, NHS and Health Department for Children Schools and Families 2007). Scottish schools are required by the Schools (Health Promotion and Nutrition) (Scotland) Act 2007 (Scottish Government 2007) to be 'health promoting'. Local authorities are expected to provide resources and facilities to promote the mental health of pupils and to support pupils experiencing low-level mental health problems. This shift has occurred within the context of a wider inter-agency approach whereby all professionals working with children are charged with responsibility towards mental health (Public Health Institute for Scotland 2003). Successful inter-agency co-operation between schools, education psychologists and mental health services is seen to be critical, although doubts have been expressed about the efficacy of professional interactions at these interfaces (Connelly 2008, Rothi et al 2008). As health professionals in educational settings, nurses in schools have the potential to play a key role, as outlined in A Scottish Framework for Nursing in Schools (NHS Scotland 2003).

This paper draws from a study funded by the Scottish Government's National Programme for Improving Mental Health and Well-being. The study arose from observations made during previous school-based research undertaken by the authors (Shucksmith et al 2005, van Teilingen et al 2008). Findings suggested that in some settings the role of the school nurse was overlooked, owing to her unique, and sometimes isolated, position in the school community. This view is shared by Crogan et al (2004) who wrote, 'School nursing in the United Kingdom has long considered 
itself to be an invisible service whose philosophy and practices are misunderstood within and outside the health service' (p385). In particular, as the profile of young people's mental health has been raised, the developing role of nurses in this field is currently under-researched.

In the UK the role of the school nurse is being redefined as the focus of the health service moves more towards a public health model (Molloy and Caraher 2000), with a shift from a purely medical understanding to a social model of health care (Bunton et al 1995). The public health perspective takes account of the social contexts of health difficulties, with a focus on early intervention, prevention and health promotion (Ashton and Seymour 1988).

In Scotland, following publication of Nursing for Health (NHS Scotland 2001), the role of community public health nursing was reviewed with plans to restructure the service by amalgamating school nurses, district nurses and health visitors within locality teams. More recently this policy change has been revised but the process has raised questions about the role and the future of school nursing. In common with the wider UK it is clear that regional variation exists at strategic and operational levels (Wicklander 2005). This paper therefore offers a timely interrogation of the mental health work of school nurses, and raises some key issues. 
Whilst the paper is located in the Scottish policy context, the issues raised are applicable beyond national boundaries, and are potentially of interest to other professionals who offer tier $1^{1}$

support to the mental health of young people. The paper discusses the provision of supportive relationships in forms which are meaningful and accessible to young people.

The paper takes this format: The following section provides a context for the mental health work of school nurses by discussing the role of relationships in the development of resilience. This section closes with two research questions. Then the data collection and analysis are described. Subsequently the findings are presented in two sections corresponding to the research questions. The paper continues by discussing the findings in the context of young people's views of supportive relationships, and the tensions inherent in the role of the nurse in school. A short conclusion highlights some key issues for the future of nursing in schools.

\section{Relationships, resilience and mental health}

Within youth research there is renewed interest in the role of relationships in young people's lives. It has long been acknowledged that relationships with others often play a pivotal role for young people in negotiating their social worlds, but recent research has drawn attention to ways in which this may be harnessed to promote resilience among those who have faced disadvantage. The concept of resilience has been defined as the capacity of some individuals to overcome disadvantage and to 'bounce back' from adversity (Masten and Coatsworth, 1990).

\footnotetext{
${ }^{1}$ CAMHS services are structured in a four-tiered model (although many services do not fall neatly into tiers). Tier 1 is the primary care that is provided by professionals who are not mental health specialists, such as nurses, teachers and social workers (Appleton 2000)
} 
Rutter (2004) has highlighted the importance of strong and consistent relationships in building the capacity of young people to overcome barriers, including poor mental health. Similarly, factors such as poor relationships, the absence of strong social networks and fragmenting or abrupt ending of significant relationships appear to be undermining of mental health (Gilligan, 1999). At the same time, constructing and organising social relationships are part and parcel of growing up.

The important role of relationships with professionals in supporting young people has been noted by a number of studies. Such constructive and continuing support can supplement existing relationships (Daniel 2005). By providing a sounding-board or a safe space with a trusted adult, these relationships may be particularly salient for young people experiencing mental health difficulties, and can prevent the escalation of problems (Clayden and Stein, 2005). While resilience encompasses a range of themes, a major area of interest has been the role of strong relationships in mitigating disadvantage or adversity (Gilligan, 1999; Daniel 2005).

Thus it is important to explore what young people value in their relationships with adults. Previous work by the authors has highlighted a range of qualities that were appreciated by young people in adults described as mentors (Philip et al, 2004; Philip and Spratt 2010), including respect for the young person, continuity, confidentiality, trustworthiness, and viewing the young person as a capable and active partner in the relationship. 
A number of other studies have identified features that young people value in service providers, and there is clear reinforcement between the studies. Kidger et al (2008), identify the importance to young people of confidentiality (both in accessing and in subsequent dealings with the service), availability, accessibility and the ability to provide information. In a similar vein, the interim report of the National Child and Adolescent Mental Health Services (CAMHS) Review (2008) reported that children, young people, parents and carers valued an approach in which they felt listened to and involved in actions taken. Particularly, the report noted, they appreciated continuity of staff, involvement in decisions about services and interventions, easier access to information about services, earlier intervention to avoid crises, services provided in places which were convenient, and co-location of services to avoid stigma and promote confidentiality. Wager et al (2007) identified the school as a 'vital hub' for young people's engagement with services, pointing out that the co-location of other services with education was of particular importance for those in lower income households, who may have fewer opportunities to access services.

Equally, it is reported that poor relationships with supporting adults can fail to deliver the support young people seek. Young people reported dissatisfaction with professionals who took a blaming approach, who dismissed their views, who failed to consult them, or who medicated too readily (Haydock 2001). The response of some young people to the experience of over-controlling relationships was to withdraw (Haydock 2001, Woodgate 2006).

This paper explores nurses' role in supporting mental health by focussing on two research questions. Firstly, what (in their own view) is the distinctive contribution 
made by nurses in school to young people's mental health? In considering this we explore the extent to which school nurses view their role as enhancing resilience. Secondly, what are the tensions and challenges faced by nurses in delivering mental health support in schools?

Interviewees described the work of nurses in terms of broad categories of: individual support, targeted support for specific groups, whole-class/whole-school mental health promotion and building the capacity of the school to respond to mental health issues. In this paper we concentrate on the support that nurses give to individual young people. In choosing this focus, we do not seek to undervalue the importance of wholeschool approaches to mental health, nor to overlook the role of nurses in such endeavours. We have argued elsewhere (Spratt et al 2006) that individualised approaches are most meaningful in the context of a wider mental health promoting school environment. However, nurses' contribution to whole-school efforts are more visible and, hence, better understood than their work with individual young people. We concentrate here on the aspect of their work that is often less evident.

\section{Methods}

Scotland is a varied country, with many remote and rural communities and a number of sizeable urban settlements. Significant inequalities in health and income persist (Scottish Government 2009). This study was designed as a national survey, to capture variations in policy and practice. All fourteen Scottish health boards were invited to participate, and thirteen did so. To elicit information about practice in the context of national and local policy, the study sought the views of managers of nurses in schools. Two managers per health board were invited to take part, and twenty-five interviews took place. 
Since management structures differ across the country, suitable participants were identified in consultation with the Executive Director of Nursing (or equivalent) in each health board. Where more than two school nurse management posts existed, selection was directed towards those with an interest in mental health. The interviewees held a variety of positions, some being entirely strategic while others were line managers carrying an operational nursing caseload. For the purposes of this paper we refer to them collectively as 'managers'.

Paying attention to the ethical aspects of recruitment (Denscombe 2002), the managers were approached by letter, informing them of the purposes of the study, their role, should they consent, together with assurances of confidentiality, anonymity and data security. To ensure that sufficient detail was provided for their informed decision (Kimmer 1988), the letter was followed by a phone call to discuss the project, before an appointment for an interview was made. Participants were made aware that they could withdraw at any time.

Owing to the geographical spread of participants, telephone interviews were conducted. A semi-structured format was adopted, taking the form of a 'conversation with a purpose' (Burgess 1984 :102). A topic-centred approach was taken, giving space for participants to develop the areas of most interest to them, and to allow for innovative ideas or unexpected responses (Masson 1998, Denscombe 2007).

Interviews were recorded, with the consent of the participants, and fully transcribed. One interviewee declined to be recorded, so extensive notes were taken. Analysis was 
supported by the use of the software package NVivo 7, to aid in the organisation of coding of themes emerging from the data. Two researchers undertook the analysis to allow for cross checking of coding and provide consistency in the interpretation.

Participants were drawn from a relatively small community and therefore confidentiality in handling the data and anonymity in reporting were of the utmost importance. When reporting, health boards were not identified, participants were each allocated a number, and other distinguishing attributes were removed from the data. Ethical approval was granted by the NHS by application to the Multi Research Ethics Committee Scotland. Research and development approval was obtained by application to Multicentre Research and Development Scotland.

It should be noted that that we report the viewpoints of those who are in a strategic position in delivering the service. In this small study the views are not counterbalanced with those in other positions, particularly users of the system, although they are contextualised within the wider literature.

\section{Findings}

At the time of the study, a major restructuring of school nursing was underway in Scotland resulting in organisational diversity across the country. The majority of health boards had retained the traditional model of one named nurse linked to each secondary school and its associated primaries. One health board had organised its public health staff into locality teams which acted 'corporately' so individuals were not linked to particular schools. The remaining boards were at different stages in the transition. Consequently various terms were used to describe nurses working in schools, such as 'school nurse', 'public health nurse', or 'public health nurse for 
schools'. For simplicity, the paper will use the term 'nurse' to mean 'nurse working in school'.

Drop-in clinics were the most commonly cited activity in the survey, and were highly valued. These were staffed by nurses and were held regularly in or near secondary schools. Although they took different formats, their distinguishing feature was that young people themselves made the choice whether and when to attend. Whilst not specifically designated as a mental health service, a significant proportion of issues presenting at the clinics were reported to include a mental health component. Commonly young people sought sexual health advice, but interviewees were aware of the links between sexual and mental health, and reported that nurses would address both. Where nurses did not offer drop-in clinics they often referred to an 'open door policy' although this could be hampered by limited availability of staff.

Nurses also worked individually with young people who had been referred by other professional groups. For example, teachers may refer children involved in bullying, or those who they believed had issues with self esteem. In particular, nurses reported an increasing proportion of their time being devoted to child protection.

Analysis of the interview data is presented in two sections below, corresponding to the research questions.

\section{a. Nurses in school: a distinctive contribution to mental health?}

Interviewees overall viewed the role of nurses as unique. Their justification for this view was evident in four main themes emerging from the data. Firstly, they felt they built relationships of trust that developed over time. Secondly they offered 
confidentiality, albeit within limits. Thirdly, whilst being available within the school, they were in some ways detached from the school system, having limited involvement in teaching, assessment or discipline. And fourthly, being trained nurses working within a public health model, they combined medical expertise with a 'holistic' perspective. These themes are elaborated below.

Relationships of trust.

Continuity was deemed to be a critical feature of relationship building and, in turn, enhancing resilience. Participants argued that nurses could become a well-known face to young people, as they often spanned the transition from primary to secondary schools. Their routine presence in school, together with some involvement in curriculum delivery, could lead to familiarity. The efforts of individual nurses to develop their profile and to foster good relationships were seen as paramount, as the two excerpts below demonstrate:

If they build up a rapport with the children [...], the children feel they can approach them. And...particularly when they are working with the feeder primary schools, the children have known them, you know, from early on. So before they hit the secondary stage, it's a known face and somebody that they can trust. So I think... and I suppose consistency too and continuity. (Manager 14)

Well, school nurses are [...] the only health professionals that are in schools that are accessible to children, that children trust, they build up relationships with children because they are seen about the school. (Manager 6) 
One interviewee pointed out that nurses' curricular speciality was sex and relationships education. This school-wide role identified them as willing to talk openly about so-called 'delicate' issues, and therefore contributed to their individual relationships with children.

I think we might be seen as we are the ones that talk about difficult subjects such as sex education, things like that which...I think they probably even at that young age feel they can come and talk to...things that affect themselves. (Manager 3)

Often then there was an implicit assumption that nurses provided opportunities for relationships with young people that differed from those that young people have with other adults in school. This was linked to confidentiality, as explored below.

\section{Confidentiality}

Interviewees repeatedly contrasted their approach to confidentiality with that of other professionals. They reported that young people were aware that information divulged to nurses would not normally be passed to others without their full knowledge and consent (although the protocols surrounding information-sharing in child protection cases were made explicit). This was claimed to be a significant reason why young people might seek help from the school nurse.

So I think there is that confidentiality sometimes, something that is...that gives them a bit of comfort, they don't want everybody to know and they... if they 
start to build up a trust they know that this is not something that everybody is going to know about. (Manager 17)

Guarantees of confidentiality, linked to the generalist nature of the service, offered some defence against fears of potential stigma associated with attendance at drop in clinics.

A child can go to see a school nurse and nobody knows what that child is going in for so it's very non-stigmatising. (Manager 6)

A number of interviewees pointed out that the location of nursing services within schools enhanced young people's autonomy. By offering medical support during the school day, young people could seek advice without the knowledge of others including their parents. This was seen to be particularly important in rural settings, where young people were often unable to travel to other health services without parental knowledge. In this way the young person was assumed to be capable to making decisions, and this in itself could contribute to feelings of self-agency and of resilience.

\section{Being detached from the education system}

Having little involvement in teaching or discipline, interviewees claimed nurses could focus non-judgementally on the well-being of individuals. This, they felt, impacted upon the children's willingness to approach and confide in nurses. 
I think sometimes children see a school nurse as kind of a bit different from a teacher, because they are actually not in the classroom all the time. They are not...maybe not authoritarian; they are not kind of seen in that kind of light. (Manager 11)

Nurses were described as being somewhat set apart from the day-to-day life of the school. Young people's visits to the nurse were confined to a particular space, both physical and psychological. By contrast, the teachers' routine presence, and their role in a class setting may, interviewees reported, deter some young people from seeking their support, as described below:

It's difficult to tell your geography teacher that you are purging yourself with laxatives, when you know the next day they may well be giving you a ticking off for not doing your homework. (Manager 19)

The notion of 'not being teachers' came through very strongly in the interviewees' accounts. Whilst nurses were keen to support schools and collaborate with teachers, they valued their separate role. They attached great importance to their unique position as simultaneously insiders and outsiders to the school system.

A public health model

As a result of their training, nurses argued that they brought a distinctive perspective to their work. A dominant theme was their 'holistic' approach. The term 'holistic' was used variously to describe a way of viewing a young person as a whole being (as opposed to focussing on one aspect), as a way of contextualising young people within 
the family and community setting and also as a term to describe their own ability to work between a range of agencies.

Within an education setting they are the only people who offer a health input. And health touches on everything in terms of what the child or young person is doing in terms of their ability to learn, ability to cope, their peers. It's all related to mental health, isn't it? (Manager 7)

Unlike other colleagues in the education sector, nurses could access health records and claimed that this enabled them to understand some issues, including family circumstances, which were not available to other professionals working in the school setting.

I think as well nurses tend to kind of maybe see the bigger picture and maybe have other information from other agencies, about this particular child. (Manager 11)

Nurses also were seen to possess an understanding of health and a knowledge of services that enabled them to offer advice and support from a particular standpoint'

We can also bring that in with other health information, not just look at the mental health and well-being. We can bring in things like lifestyles, risk taking behaviours, ... accessing the right service for them. (Manager 9) 
Finally, the skill and willingness to collaborate with other agencies was highlighted as a key element of the nurses' toolkit. One participant described school nurses as the 'original interagency worker', having, she claimed, pre-empted the current policy drive towards collaborative working. Their familiarity with the work of other services, their ability to direct young people to an appropriate service, facilitated by their contacts, were viewed as pivotal to their role in building relationships with young people.

\section{b. Tensions and challenges}

Whilst interviewees identified the potential of nurses to support mental health in schools, they also reported frustrations at the lack of capacity to fulfil this role in meaningful and equitable ways. In this section we report on tensions and challenges faced by the nurses and their managers in attempting to offer a service which addressed mental health, alongside the range of other core activities. The main challenges were reported to be resources, training and tensions between proactive and reactive strategies.

\section{Resources}

All participants reported limited capacity to deliver a comprehensive service. Variability in the staffing levels was evident within and between health boards, with some individuals carrying very large caseloads. For example:

There are supposed to be one nurse to 1700 pupils. We are currently sitting at one nurse to 4,500 pupils. (Manager 13)

The following metaphor represents a widely held view: 
...traditionally because there has been a lack of investment, you know, really, I suppose the way I see it, it's like somebody has taken a piece of pastry to roll, to go over a pie, but unfortunately there are holes all over that pie! And the apples underneath keep getting burnt. (Manager 6)

These comments raise questions about the realism of claims to develop supporting relationships with individual young people.

A minority of health boards reported significant gaps in provision, with some areas lacking any school-based nursing. In other cases the service was funded through a series of short term arrangements, with implications for the quality and continuity of relationships with young people and staff in schools. Interviewees also argued that a low priority was attached to their role by some schools; for example, some commented on the poor accommodation available. Moreover, when space was limited, nurses could find themselves competing with other school activities. As one interviewee remarked,

Challenges? Well...it's...I think for us it's hanging on to our school nurse room within the school, just physically having a place. (Manager 17)

Lack of resources in other agencies resulted in several interviewees reporting they were a 'holding station' for young people on waiting lists for specialist mental health services. Intensive work with young people who could be more appropriately 
supported elsewhere reduced the overall capacity of nurses to develop relationships with those in less acute difficulty.

\section{Training}

Concerns were voiced about the opportunities to keep abreast of developments in mental health. Whilst all interviewees acknowledged the responsibilities of nurses in this field, and the progress made, some expressed doubt about how adequately some were prepared. At a conceptual level, nurses appeared to have little opportunity to explore the theoretical implications of their approach.

It was reported in some cases that nurses lacked awareness of their role in supporting mental health.

We have still got a lot of nursing staff that don't recognise their own role in mental health. They think it's part of somebody else's role, it's almost like ... you know, if somebody has got depression, well they have to see a CPN, or a child and adolescent mental health nurse. (Manager 21)

In other cases nurses were perceived as aware, but uncertain about how to enact their role. Lack of skills and/or confidence were commonly reported as undermining nurse activity. With insufficient training, it was also reported, nurses may be unable to identify serious difficulties and refer appropriately to other agencies.

However, even where good quality training was theoretically available, the resource allocation often did not include a training budget. And where the budget did meet 
course fees, it usually did not pay for 'back-fill' (cover). Ironically, attending training resulted in short term reduction of support.

\section{Tensions between proactive and reactive strategies}

Tension was evident between 'upstream' promotion of mental health and daily crisis management. In particular, issues relating to child protection were reported as increasingly time consuming. The number of cases that nurses dealt with, and the administrative procedures associated with each case, had risen markedly.

....the child protection demands, they are huge now. There has been a change in the procedures recently, which means there is a huge knock-on effect not only in our day to day work but our paperwork. (Manager 9)

One interviewee talked about the inherent difficulties in the decisions faced on a dayto-day basis. Whilst health promoting activities were generally scheduled in advance, mental health supporting activities were unpredictable and often urgent. Hence nurses needed to operate two different and sometimes incompatible approaches to time management. One interviewee described a typical dilemma:

She would have to make a clinical decision. Does she scrap the health promotion talk that she is going to do that day? If a young person comes along and says "I have been self-harming and, by the way, I think I am pregnant", I know where my priorities would lie on that day. And anything else can wait. So it's very much a clinical decision you make at that time. (Manager 19) 
The tension between the proactive and the reactive functions raises fundamental questions about the role of nurses in relation to young people's mental health. Clearly nurses could, potentially, work across the spectrum from health promotion, to low level support and advice, to child protection, yet the limited capacity compels prioritisation. There was some evidence of strategic planning to move the focus of nursing in schools towards reactive support.

\section{Discussion}

Schools throughout the UK are increasingly expected to promote mental health through both the formal and informal curriculum (Scottish Executive 2004, NHS and Health Department for Children Schools and Families 2007). Strategies such as teaching emotional literacy (Weare 2004) and resilience (Knight 2007) are evident in some areas of the UK. Nonetheless, there remains a wider gap between the emotional well-being of young people within individual schools than exists between that of young people from different schools (Gutman and Feinstein 2008). This points to a need for services which are responsive to the requirements of individuals within schools.

The structuring of children's services has, in recent years, begun to respond to conceptualisations of children as active agents rather than passive recipients of adult direction (James and Prout 1997). This new understanding, coupled with the development of a legal framework of children's rights, places significance on the views of young people. Whilst this paper concentrates on the views of professionals, there is a growing literature which consistently reports that, in the views of young people, the quality and consistency of the relationship is central to the success of any 
professional support (Haydock 2001, Woodgate 2006, CAMHS 2008, Kidger et al 2008,). This has been highlighted in other arenas, such as youth mentoring, where young people reported the value of relationships with adults who have time to talk, and who do not respond in a judgemental way (Philip et al 2004, Clayden and Stein 2005). Similarly, Hallett et al (2003) have reported that, when seeking help, young people were highly selective, actively seeking out adults whom they perceived as trustworthy.

Where well supported, nurses in schools can meet the criteria which young people are reported to value, offering a low threshold non-stigmatising service where those who seek help are not labelled, by others, as problems. The autonomy to seek help when and if they choose to do so allows a level of choice which is not always apparent amongst services that are linked with schools (Spratt et al in press). In rural settings the school nurse may offer the only confidential service that young people can access. This is particularly important in Scotland.

Not only can nurses in schools structure their support in ways which young people find accessible and helpful, the type of relationships that can develop resonates with what is currently understood about resilience. Their constructive and consistent support may supplement existing relationships and, for some young people experiencing difficulties, contribute to the development of resilience, which in turn can help them to cope with adversity and to maintain positive mental health (Gilligan 1999, Rutter 2004, Daniel 2005). This tentative assertion merits more detailed research. 
However, it is important not to over-state the impact of the nurse in schools. This paper demonstrates that the potential of nurses is undermined by lack of capacity coupled with diverse and sometimes conflicting demands, and competing conceptualisations of their role. As in other children's services, where resources are scarce, the priority tends to lie with reactive responses to crises often linked to child protection, rather than more upstream support of the wider population (Jack 2006), raising questions as to whether the nurse's role is to engage with issues that young people deem to be important or to deliver adult agendas driven by existing policy.

This paper reports on a small exploratory study which was confined to analysis of managers' perceptions of nursing in schools. Further work is required to explore young people's specific views of the services offered by nurses in schools, and the links that may be made to the development of resilience. In addition, work on how the role of the school nurse can better interact with teachers, parents and young people in building and enhancing resilience is urgently required.

\section{Conclusion}

The nursing service in schools is at a pivotal point in Scotland. As the service is restructured and the role of the nurse reconfigured, any proposed changes could impact upon the capacity of nurses to offer individualised support to young people's mental health. Any move from a school-based, child-centred service to a communitybased, family-centred service requires to be carefully structured in order to safeguard opportunities for the young person who wishes to seek confidential advice. As noted by Warin (2007), the interests of family members may not always coincide, and arguably the dissonance between individual interests may be more apparent as young people reach their teenage years. 
This study has identified an important, hitherto unsung, role of nurses in building trusting relationships that may contribute to development of resilience. Hence any changes in the structure of the school nursing service should build on existing strengths and draw from what is known about young people's preferences to make the service more widely accessible across a range of settings. It should concentrate on drawing young people in by building on those features that they have repeatedly been reported to value.

\section{References}

Appleton P (2000) Tier 2 CAMHS and its interface with primary care. Advances in Psychiatric Treatment, 6: 388-396

Ashton, J. and Seymour, J. (1988) The New Public Health. Buckingham: Open University Press.

Bunton, R., Nettleton, S. and Burrows, R. (1995). The Sociology of Health Promotion: Critical Analysis of Consumption Lifestyle and Risk. London: Routledge.

Burgess, G (1984) In the Field: An introduction to field research. London: Allen and Unwin

CAMHS (2008) Children and young people in mind Final report of the National CAMHS Review.

http://www.dcsf.gov.uk/CAMHSreview/downloads/CAMHSReview-Bookmark.pdf accessed 24.02.2010 
Clayden, J. and Stein, M. (2005) Mentoring Young People in Care: 'Someone for me' York: Joseph Rowntree Foundation.

Connelly, G., Lockhart, E., Wilson P., Furnival, J., Bryce, G., Barbour, R. and Finn, L. (2008) Teachers' responses to the emotional needs of CYP. Results from the Scottish Needs Assessment Programme. Emotional and Behavioural Difficulties 13 (1) $1-13$.

Crogan, E., Johnson, C. and Aveyard, P. (2004) School nurses: policies, working practices, roles and value perceptions. Journal of Advanced Nursing 47 (4) 377-385.

Daniel, B. (2005) Resilience: a framework for positive practice. Scottish Executive Education Research Programme Research Findings Series No 5. (with Sally Wassell) www.scotland.gov.uk/social research.

Denscombe, M. (2007) The good research guide Maidenhead: Open University Press

Denscombe, M (2002) Ground rules for good research. Maidenhead: Open University Press.

Gilligan, R. (1999) Enhancing the resilience of children and young people in public care by mentoring their talents and interests. Child and Family Social Work 4 187196. 
Green, H., McGinnity, A., Meltzer, H., Ford, T. \& Goodman, R. (2005) Mental health of children and young people in Great Britain 2004 (Basingstoke, Palgrave Macmillan). Also available online

at: http://www.dh.gov.uk/assetRoot/04/11/83/39/04118339.pdf. accessed 24.02.2010

Gutman, L. and Feinstein, L. (2008) Children's Well-being in Primary School: Pupil and school effects. Wider Benefits of Learning Research report 25. London: Institute of Education.

Hallett, C., Murray, C. and Punch S. (2003) Negotiating pathways in Prout, A. and Hallett, C. Hearing the voices of children: Social policy for a new century. London: RoutledgeFalmer 123-138.

Haydock, E. (2001) No harm in listening Edinburgh: Penumbra.

Jack, G. (2006) The Area and Community Components of Children's Well-being Children and Society 20 (5) 334-347.

James, A. and Prout, A. (1997) Constructing and Reconstructing Childhood. London: Falmer Press.

Kidger, J Campbell R, Donovan J, Gunnell, D, Biddle, L and Starkey F (2008). An Exploration of Emotional Health Interventions in English Secondary Schools: Full Research Report, ESRC End of Award Report, RES-000-22-1462. Swindon: ESRC. 
Kimmer, A. (1988) Ethics and Values in Social Research London: Sage

Knight, C. (2007) A Resilience Framework: Perspectives for Educators. Health Education, 107, (6) 543-555.

Masson, J (1998) Qualitative Researching London: Sage.

Masten A and Coatsworth J (1998) The development of competence in favourable and unfavourable environments: lessons from research on successful children. American Psychologist, 53, 205-220.

Molloy, J and Caraher, M (2000) Public health and the role of the nurse: the need for greater clarity. British Journal of Community Nursing 5 (9) 431-435.

NHS and Health and Department for Children, Schools and Families (2007) Introduction to the National Healthy Schools Programme

http://www.healthyschools.gov.uk/Uploads/Resources/4531046c-011e-4fa6-a13856013c5dc634/Introduction.pdf accessed 24.02.2010

NHS Scotland (2001) Nursing for Health: A review of the contribution of Nurses, Midwives and health visitors to improving the public's health. Edinburgh: Scottish Executive. 
NHS Scotland (2003) A Scottish Framework for Nursing in Schools. Edinburgh: Scottish Executive.

Philip, K., Shucksmith, J. and King C. (2004) Sharing a Laugh: a qualitative study of mentoring interventions with young people. York: Joseph Rowntree Foundation.

Philip and Spratt (2010) Choosing your Friends: Young People Negotiating Supporting Relationships. Advances in School Mental Health Promotion 3 (1) $42-51$

Public Health Institute for Scotland (2003) Needs Assessment Report on Child and Adolescent Mental Health: Final Report. Glasgow: PHIS.

Rothi, D., Leavey, G. and Best, R. (2008) Recognising and managing pupils with mental health difficulties: Teachers' views and experiences on working with educational psychologists in schools. Pastoral Care in Education 26 (3) 127 - 142.

Rutter, M (2004) (Ed) Psycho-social disturbances in Young People: challenges for Prevention. Cambridge: England: Cambridge University Press.

Scottish Executive (2004) A Curriculum for Excellence: The Curriculum review group. Edinburgh: Scottish Executive.

Scottish Government (2007) Schools (Health Promotion and Nutrition) (Scotland) Act 2007 Edinburgh: The Stationery Office.

http://www.opsi.gov.uk/legislation/scotland/acts2007/pdf/asp 20070015 en.pdf 
accessed 24.02.2010

Scottish Government (2009) Poverty and income inequality in Scotland: 2007/08. A National Statistics Publication for Scotland.

Available: http://www.scotland.gov.uk/Resource/Doc/933/0081018.pdf accessed 24.02.2010

Shucksmith, J., Philip, K., Spratt, J. and Watson, C. (2005) Investigating the links between mental health and behaviour in schools. Edinburgh: Scottish Executive Available: http://www.scotland.gov.uk/Resource/Doc/76169/0019851.pdf accessed 24.02.2010

Spratt J, Shucksmith J, Philip K and Watson C (in press) 'The bad people go and speak to her': Young people's choice and agency when accessing mental health support in school. Children and Society.

Spratt, J, Shucksmith J, Philip, K and Watson C (2006) "Part of who we are should include responsibility for well-being”. Links between the school environment, mental health and behaviour. Pastoral Care in Education 24 (3) 14-21.

van Teijlingen, E, Tucker, J., Philip, K., Spratt, J., Poobalan A., Pitchforth E., Imamura, M., Forbes, S. and Vascianovich, A (2008) A Review of Sex and Relationships in Scottish Secondary Schools Edinburgh: Health Scotland. 
Wager, F., Bailey, N., Day, R., Hamilton, D., Hill, M and King, C. (2007) Serving

Children? The impact of poverty on children's experiences of services. Save the Children and University of Glasgow

Available http://www.savethechildren.org.uk/en/docs/serving-children.pdf accessed 24.02.2010

Warin, J. (2007) Joined-up services for young people and their families: Papering over the cracks, or re-constructing the foundations? Children and Society 21 (2) 87-97

Weare, K. (2004) Developing the Emotionally Literate School. London: Sage.

Wicklander, M. K. (2005) The United Kingdom Healthy School Standard: a framework for strengthening the school nurse role. Journal of School Nursing 21 (3) $132-8$.

Woodgate, R. L. (2006) Living in the shadow of fear: adolescents' lived experience of depression, Journal of Advanced Nursing, vol. 56, no. 3, pp. 261-269.

World Health Organisation Europe (2005) The health of children and adolescents in Europe. Fact Sheet Euro/06/05 available:

http://www.euro.who.int/document/mediacentre/fs0605e.pdf accessed 24.02.2010 